\title{
O Papel do Conhecimento do Nome das Letras no Início da Aprendizagem da Leitura: Evidência de Indivíduos com Síndrome de Down
}

\author{
Modularity of Action Programs in Normal and Down Syndrome Individuals
}

\author{
Cláudia Cardoso-Martins ${ }^{\mathrm{a} *}$, Mirelle França Michalickª, \& Tatiana Cury Pollo ${ }^{\mathrm{b}}$ \\ ${ }^{a}$ Universidade Federal de Minas Gerais, ${ }^{b}$ Washington University in Saint Louis
}

\begin{abstract}
Resumo
O presente estudo investiga as estratégias que indivíduos com síndrome de Down utilizam para aprender a ler palavras no início da aprendizagem da leitura. Indivíduos com síndrome de Down que conheciam ou não o nome das letras aprenderam a ler dois tipos de grafias simplificadas: grafias fonéticas, em que as letras correspondiam a sons na pronúncia das palavras (Ex.: BTRA para beterraba) e grafias visuais, em que as letras não representavam sons na pronúncia das palavras, mas eram visualmente mais salientes (Ex.: $\mathrm{U}^{\mathrm{Q}} \mathrm{L}^{\mathrm{G}}$ para detetive). Os resultados questionam a hipótese de que indivíduos com síndrome de Down aprendem a ler visualmente. Os indivíduos que não conheciam o nome das letras acharam ambos os tipos de grafia muito difíceis. Por outro lado, os indivíduos que conheciam o nome das letras acharam as grafias fonéticas significativamente mais fáceis do que as grafias visuais.

Palavras-chave: Síndrome de Down; estratégia de leitura; conhecimento das letras.
\end{abstract}

\begin{abstract}
This study investigates the reading strategies that are used by individuals with Down syndrome when they begin to learn to read Portuguese. Individuals with Down syndrome who knew or did not know the name of the letters learned to read two types of simplified spellings: phonetic spellings in which the letters corresponded to sounds in the pronunciation of words (e.g., BTRA for beterraba 'beet'), and visual spellings in which the letters bore no relationship to sounds in the pronunciation of words, but which were visually more outstanding (e.g., $\mathrm{U}^{\mathrm{O}} \mathrm{L}^{\mathrm{G}}$ for detetive 'detective'). Results questioned the view that individuals with Down syndrome learn to read visually. The individuals who did not know the name of the letters found both type of spellings very difficult. In contrast, the individuals who knew the name of the letters learned the phonetic spellings more easily than the visual spellings.

Keywords: Down syndrome; reading strategy; letter-name knowledge.
\end{abstract}

O presente estudo investiga o impacto do conhecimento do nome das letras sobre as estratégias que indivíduos com síndrome de Down utilizam para aprender a ler palavras no início da alfabetização. Conforme descrevemos a seguir, existe evidência de que a aprendizagem do nome e do som das letras impele as criancas a aprender a ler através do processamento e memorização de relações letra-som nas palavras. O presente estudo investiga em que medida isso também ocorre entre indivíduos com síndrome de Down.

De acordo com vários modelos da aquisição da leitura (Ex.: ver Frith, 1985; Gough \& Hillinger, 1980), quando as crianças começam a ler, elas não processam relações entre as letras na grafia das palavras e os sons na sua pronúncia. Ao invés disso, as crianças começam a aprender a ler através da formação de uma associação entre uma característica saliente na grafia da palavra ou em torno dela e o seu significado e/ou pronúncia. Por exemplo,

Agradecimentos: ao CNPq e aos indivíduos com síndrome de Down que concordaram em participar do estudo.

* Endereço: Departamento de Psicologia, UFMG, Av. Antonio Carlos, 6627, Pampulha, 31270 901, Belo Horizonte, MG. Fone: (31)34996270.cacau@fafich.ufmg.br elas podem reconhecer o sinal McDonald por causa do arco dourado que aparece atrás do seu nome. Frith chamou essa estratégia de logográfica em analogia aos sistemas logográficos de escrita em que os sinais gráficos representam significados ou palavras inteiras. Segundo alguns estudiosos (Gough \& Hillinger, 1980; Seymour \& Elder, 1986), as crianças podem aprender a ler um número relativamente grande de palavras dessa maneira. Todavia, a estratégia logográfica apresenta duas limitações importantes. Em primeiro lugar, ela é altamente imprecisa. Ou seja, palavras com grafias semelhantes são freqüentemente confundidas (Ex.: a criança que aprendeu a ler mamãe por causa do 'til' pode confundir as palavras maçã, lã, etc., com a palavra mamãe). Além disso, ela não possibilita a leitura de palavras desconhecidas. Em virtude dessas limitações, a estratégia logográfica eventualmente cede lugar para a estratégia alfabética, ou seja, para a habilidade de ler através do processamento e recordação das relações letrasom nas palavras. 
De acordo com a teoria de fases de Ehri (1992, 2002), o maior ímpeto para a utilização da estratégia alfabética é a aprendizagem do nome e do som das letras. Segundo Ehri (1992, 2002), a criança que conhece o nome e/ou som das letras utiliza esse conhecimento para ler palavras desde o início da aprendizagem da leitura. A razão é simples: a habilidade de ler através do processamento das relações letra-som fornece à criança um procedimento sistemático e, portanto, mais confiável do que a estratégia logográfica. Inicialmente, no entanto, a criança só é capaz de processar relações letra-som para algumas letras nas palavras, talvez a primeira letra ou a primeira e a última letras. Por exemplo, ao ver e escutar a palavra bebê, a criança pode notar que a letra $B$ no início da palavra corresponde ao som /be/que ela é capaz de detectar no início da forma oral da palavra. Essa compreensão possibilita-lhe criar uma rota de acesso à memória que contém informação visual e fonológica. Como resultado, a criança recupera tanto o significado como a pronúncia da palavra na próxima vez que ela vir a sua grafia. Como esse exemplo sugere, a representação da palavra é inicialmente bastante incompleta, algo como $\mathrm{B}_{-}-$ _, o que leva a criança a fazer confusões entre palavras com grafias semelhantes (Ex.: lendo bala ou bola como bebê). Ehri denominou essa fase de alfabética parcial para distinguí-la da fase posterior, quando a criança começa a ser capaz de ler através do processamento de todas as correspondências letrasom na palavra.

Ehri e Wilce (1985) mostraram a importância do conhecimento do nome e/ou som das letras para a emergência da habilidade de ler através do processamento de relações letra-som. Ehri e Wilce avaliaram a habilidade de crianças pequenas de aprender a ler dois tipos de grafias simplificadas: grafias fonéticas, em que as letras correspondiam a sons na pronúncia das palavras (Ex.: JRF para a palavra giraffe 'girafa') e grafias visuais, em que as letras eram visualmente salientes, mas não apresentavam qualquer relação com os sons na pronúncia das palavras (Ex.: BC para giraffe). Três grupos de crianças participaram do estudo: os não leitores, isto é, as crianças que leram menos do que duas palavras em um teste de leitura de palavras freqüentes em livros para crianças pequenas; os leitores iniciantes novatos, isto é, as crianças que leram entre duas e 10 palavras e, finalmente, os leitores iniciantes veteranos, isso é, as crianças que leram mais do que 11 palavras corretamente. De acordo com Ehri e Wilce, o grupo de préleitores aprendeu a ler as grafias visuais mais facilmente do que as grafias fonéticas. Por outro lado, ambos os grupos de leitores iniciantes acharam as grafias fonéticas significativamente mais fáceis do que as grafias visuais. Esses resultados sugerem que o progresso na aprendizagem da leitura, mesmo o progresso inicial, pressupõe a habilidade de processar relações letra-som na palavra. Ehri e Wilce argumentaram que essa habilidade, por sua vez, baseia-se no conhecimento do nome e som das letras. Com efeito, os grupos de leitores conheciam um número significativamente maior de nomes e sons de letras do que o grupo de crianças pré-leitoras.
Resultados semelhantes foram obtidos para crianças e adultos não alfabetizados falantes do português (de Abreu\& Cardoso-Martins, 1998; Cardoso-Martins, Resende, \& Rodrigues, 2002; Cardoso-Martins, Rodrigues, \& Ehri, 2003). De Abreu e Cardoso-Martins (1998) ensinaram crianças brasileiras em idade pré-escolar a ler grafias simplificadas visuais e fonéticas, semelhantes às grafias utilizadas por Ehri e Wilce (1985). Dois grupos participaram do estudo: crianças que conheciam o nome das letras e crianças que não conheciam o nome das letras. As crianças sem conhecimento do nome das letras aprenderam a ler as grafias visuais mais facilmente do que as grafias fonéticas, enquanto o padrão oposto ocorreu para as crianças que conheciam o nome das letras.

No estudo de Abreu e Cardoso-Martins (1998), o nome da primeira letra na grafia fonética podia ser claramente detectado na pronúncia de todas as palavras (Ex.: a grafia CBA para cebola, em que o nome da letra C pode ser claramente detectado na pronúncia da palavra). É possível, portanto, que as autoras tenham tornado a tarefa relativamente fácil para as crianças (Ex.: ver Treiman, Tincoff, \& RichmondWelty, 1996). Recentemente, no entanto, Cardoso-Martins et al. (2002, 2003) mostraram que tanto crianças como adultos analfabetos utilizam o seu conhecimento do nome das letras para aprender a ler grafias simplificadas em que as letras correspondem a fonemas contidos no nome das letras e não ao nome inteiro das letras.

O objetivo do presente estudo foi investigar a generalização desses resultados para indivíduos com síndrome de Down (SD). A síndrome de Down apresenta um contexto particularmente interessante para a investigação da hipótese de que o conhecimento do nome das letras estimula as crianças a aprender a ler através do processamento e memorização das relações letra-som nas palavras. Como discutimos a seguir, a razão para isso resulta do padrão complexo de deficiências características da síndrome (Ex.: ver Pennington, Moon, Edgin, Stedron, \& Nadel, 2003).

A síndrome de Down é uma desordem do desenvolvimento causada pela presença de um cromossoma 21 extra. Os indivíduos com SD apresentam um atraso substancial no desenvolvimento de todas as funções cognitivas, mas algumas funções são mais comprometidas do que outras. O desenvolvimento da linguagem é particularmente prejudicado. Na realidade, as crianças com SD apresentam um escore abaixo do que seria esperado com base em sua idade mental em várias medidas de linguagem. Por outro lado, saem-se relativamente bem em tarefas de memória espacial e visual (Pennington et al., 2003). Apesar das suas dificuldades de linguagem, muitas crianças com SD aprendem a ler palavras relativamente bem. Com efeito, algumas crianças são capazes de ler palavras tão bem como seria esperado em termos da sua idade cronológica (Ex.: ver Buckley, 1985; Cardoso-Martins, Pennington, \& Moon, 2006). Buckley (1985) sugeriu que as crianças com SD saem-se bem na aprendizagem da leitura porque elas tiram proveito de suas habilidades visuais e espaciais, aprendendo a ler visualmente. 
O presente estudo contou com a participação de indivíduos com síndrome de Down com ou sem conhecimento do nome das letras. Como nos estudos descritos anteriormente, os participantes foram submetidos a uma tarefa de aprendizagem de leitura de dois tipos de grafias simplificadas: grafias fonéticas, em que as letras representam sons na pronúncia da palavra e grafias visuais, em que as letras não guardam qualquer relação com os sons na pronúncia das palavras, mas são visualmente mais salientes. Se é verdade que os indivíduos com SD baseiam-se em suas habilidades visuais e espaciais para aprender a ler (Buckley, 1985), os indivíduos com síndrome de Down que participaram do nosso estudo deveriam aprender a ler as grafias visualmente salientes com mais facilidade do que as grafias fonéticas, independentemente do seu conhecimento do nome das letras. Por outro lado, com base na hipótese de que o conhecimento do nome das letras incita as crianças a processar relações letra-som nas palavras, isso só deveria ser observado entre os indivíduos com síndrome de Down que não conheciam o nome das letras. Os indivíduos que conheciam os nomes das letras deveriam aprender a ler as grafias fonéticas mais facilmente do que as grafias visuais.

\section{Método}

\section{Participantes}

Participaram do estudo 25 indivíduos com SD (14 do sexo masculino, 11 do sexo feminino). Todos estavam matriculados em escolas atendendo a crianças e adolescentes com desordens do desenvolvimento e nenhum apresentava déficit sensorial sério. Os participantes foram divididos em dois grupos em função do seu desempenho em um teste de conhecimento do nome das letras (ver Procedimento para uma descrição do teste). Os indivíduos $(n=12)$ que nomearam 17 ou mais letras do alfabeto corretamente foram designados para o grupo com conhecimento do nome das letras. Sua idade variava entre 8 e 22 anos $(m=12,7$ anos, $d p=4$ anos). Os indivíduos que nomearam menos de 7 letras corretamente $(n=13)$ foram designados para o grupo sem conhecimento do nome das letras. Sua idade variava entre 6 e 20 anos ( $m=12,3$ anos; $d p=4,1$ anos). De uma maneira geral, nenhum indivíduo havia começado a ler por ocasião do estudo. De fato, com exceção de dois indivíduos, todos leram menos do que uma palavra corretamente em um teste de leitura contendo 30 palavras freqüentes em livros para crianças (ver Procedimento para uma descrição do teste). As duas exceções pertenciam ao grupo com conhecimento do nome das letras: um leu 9 e o outro, 4 palavras.

\section{Procedimento}

Além da tarefa de aprendizagem de leitura de palavras, todos os participantes foram submetidos a uma série de prétestes. Todos as tarefas foram administradas individualmente, na escola em que os indivíduos freqüentavam.

\section{Pré-testes}

Conhecimento do nome das letras: Os indivíduos foram solicitados a nomear 24 letras do alfabeto. As letras apareciam impressas no centro de cartões individuais, em maiúscula (fonte: Times New Roman, tamanho 72). Os cartões foram apresentados em ordem aleatória, um de cada vez.

Leitura de palavras-I. O teste consistia de 30 palavras freqüentes em livros para crianças (Pinheiro \& Keys, 1987), impressas com letras maiúsculas no centro de cartões individuais (fonte: Times New Roman, tamanho 72). Os indivíduos eram solicitados a tentar ler cada uma das palavras.

Leitura de palavras-II. Além do teste de leitura de palavras frequentes, todos os indivíduos foram solicitados a ler as palavras utilizadas na tarefa de aprendizagem de leitura de palavras. Apenas indivíduos que não puderam ler nenhuma dessas palavras foram incluídos no estudo.

Teste de Vocabulário de Peabody (Peabody Picture Vocabulary Test-PPVT, forma III-A). Esse teste avalia a extensão do vocabulário receptivo, sendo considerado uma medida de habilidade verbal. O teste consiste de uma série de 204 cartões com quatro figuras. Para cada cartão, o examinador pronuncia uma palavra e o indivíduo deve identificar a figura correspondente. Os 204 cartões são distribuídos em 12 conjuntos, segundo a ordem de dificuldade. O teste é interrompido quando o indivíduo erra oito ou mais cartões no mesmo conjunto. $\mathrm{O}$ teste foi administrado conforme as instruções especificadas no manual, com as palavras traduzidas para o português. Uma vez que não existem normas para a população brasileira, apenas os resultados brutos, isso é, o número de respostas corretas, foram considerados nas análises dos resultados.

\section{Tarefas de aprendizagem de leitura de palavras}

Dois conjuntos de 5 substantivos concretos foram selecionados para as tarefas de aprendizagem de leitura. Conforme pode ser visto na Tabela 1, grafias simplificadas foram criadas para cada uma das palavras selecionadas, grafias fonéticas, para o primeiro conjunto de palavras e grafias visuais, para o segundo. As grafias fonéticas consistiam de letras que correspondiam a sons na pronúncia das palavras (Ex.: $\boldsymbol{C B L}$, para a palavra cebola, em que as letras $c, b$ e $l$ correspondem respectivamente aos sons $/ s /$, $/ b / \mathrm{e} / l /$ ). As letras nas grafias visuais, por outro lado, não correspondiam a sons na pronúncia das palavras, mas eram visualmente mais salientes. A maior saliência das grafias visuais foi obtida graças à variação no tamanho e posição das letras (Ex.: $\boldsymbol{R}_{\boldsymbol{M}} \boldsymbol{S}$ para cabelo). Em todas as grafias fonéticas, o nome da primeira letra podia ser detectado na pronúncia da palavra. Em algumas grafias, mais de um nome de letra podia ser escutado. Esse era o caso da grafia BTRA, em que os nomes das letras $b, t$ e $a$ podem ser escutados na forma oral da palavra.

As tarefas de aprendizagem de leitura foram administradas em dias separados. A ordem de administração das tarefas foi contrabalançada entre os participantes. Para cada grupo, aproximadamente metade dos indivíduos aprendeu a ler as grafias visuais no primeiro dia e as grafias 
fonéticas no segundo dia; o restante aprendeu a ler as grafias fonéticas no primeiro dia e as grafias visuais no segundo.

Dois fantoches foram utilizados, um para cada tarefa. No início de cada tarefa, o examinador mostrava o fantoche para a criança e dizia: "Esse fantoche está aprendendo a escrever e quer que você aprenda a ler as palavras que ele escreveu”. Em seguida, os participantes eram submetidos a um ensaio de treinamento em que cada uma das cinco grafias era apresentada impressa em um cartão individual, o qual também continha uma figura ilustrando o objeto representado pela palavra. Ao mostrar cada um dos cartões, o examinador dizia: "Aqui o fantoche escreveu a palavra ..... A palavra em questão era enunciada em voz alta ao mesmo tempo em que o examinador passava o dedo indicador sob a grafia da palavra. Em seguida, o examinador pedia para o participante lê-la em voz alta. Não houve nenhum caso em que um participante não pudesse repetir a palavra.

Após o ensaio de treinamento, os participantes foram submetidos a ensaios experimentais onde eram apresentados cinco cartões, cada um contendo uma grafia simplificada impressa em letras maiúsculas (fonte: Times New Roman, tamanho 72). Os cartões eram apresentados um de cada vez e, para cada cartão, o participante era solicitado a ler a palavra que o fantoche havia escrito. As respostas corretas eram elogiadas e as incorretas, corrigidas. A ordem de apresentação dos cartões variava aleatoriamente de ensaio para ensaio. A tarefa era descontinuada após o indivíduo ter lido todas as grafias corretamente em dois ensaios consecutivos ou após 10 ensaios.

\section{Ditado das grafias simplificadas}

Após cada tarefa de aprendizagem da leitura, os participantes foram solicitados a escrever as palavras da mesma maneira como o fantoche as havia escrito. O examinador dizia uma palavra de cada vez, na mesma ordem do ensaio de treinamento.

Ao final da segunda tarefa, o examinador mostrava a grafia convencional de todas as palavras. Esse procedimento foi utilizado com o objetivo de eliminar concepções falsas a respeito da grafia das palavras.

\section{Resultados}

A Tabela 2 apresenta o número médio de respostas corretas nos pré-testes, separadamente para os dois grupos de indivíduos. Como pode ser visto nessa tabela, os dois grupos de participantes diferiram em relação ao conhecimento do nome das letras: ao contrário dos indivíduos sem conhecimento do nome das letras, os indivíduos do grupo com conhecimento do nome das letras nomearam praticamente todas as letras do alfabeto corretamente. Os dois grupos também diferiram em relação à nossa medida de inteligência verbal. Os indivíduos com conhecimento do nome das letras apresentaram um desempenho significativamente superior ao dos indivíduos sem conhecimento no PPVT.

As Figuras 1 e 2 apresentam o número médio de acertos em cada um dos 10 ensaios em função do tipo de grafia simplificada, respectivamente para os indivíduos com e sem conhecimento do nome das letras. (Os participantes que

Tabela 1

Grafias Simplificadas e Proporção Média de Respostas Corretas no Decorrer das Tentativas para cada Grafia

\begin{tabular}{|c|c|c|c|c|c|c|c|}
\hline \multicolumn{4}{|c|}{ Grafias Fonéticas } & \multicolumn{4}{|c|}{ Grafias Visuais } \\
\hline Palavras & $\begin{array}{l}\text { Grafias } \\
\text { Simplifi- } \\
\text { cadas }\end{array}$ & $\begin{array}{c}\text { Sem conheci- } \\
\text { mento das } \\
\text { letras } \\
(\text { máx }=10) \\
\end{array}$ & $\begin{array}{l}\text { Com conheci- } \\
\text { mento das letras } \\
(\operatorname{máx}=10)\end{array}$ & Palavras & $\begin{array}{l}\text { Grafias } \\
\text { Simplifi- } \\
\text { cadas }\end{array}$ & $\begin{array}{l}\text { Sem conheci- } \\
\text { mento das letras } \\
(\text { máx }=10)\end{array}$ & $\begin{array}{l}\text { Com conheci- } \\
\text { mento das letras } \\
(\text { máx }=10)\end{array}$ \\
\hline Pescoço & PQS & 3,14 & 4,82 & Geladeira & FNKO & 2,07 & 3,45 \\
\hline Beterraba & BTRA & 1,64 & 5,45 & Berço & ${ }^{\mathrm{Jx}} \mathrm{A}$ & 1,14 & 2,73 \\
\hline Zebra & $\mathrm{ZBA}$ & 2,0 & 7,18 & Cabelo & $\mathrm{R}_{\mathrm{MS}}$ & 1,57 & 4,18 \\
\hline Cebola & $\mathrm{CBL}$ & 0,78 & 5,82 & Detetive & $\mathrm{UQL}^{\mathrm{G}}$ & 1,14 & 3,36 \\
\hline Gelatina & GLIN & 2,71 & 6,18 & Chicote & ${ }^{\mathrm{B}} \mathrm{V}_{\mathrm{H}}$ & 1,71 & 3,27 \\
\hline
\end{tabular}

Tabela 2

Número Médio de Respostas Corretas (e Desvios-padrão) nos Pré-Testes e nas Tarefas de Aprendizagem de Leitura

\begin{tabular}{lcc}
\hline Tarefa & Sem conhecimento das letras & Com conhecimento das letras \\
\hline Nomes das letras (máx.=24) & $4,54(2,67)$ & $20,17(2,69)$ \\
Leitura (máx.=30) & $0,08(0,28)$ & $1,33(2,67)$ \\
PPVT - Escore bruto (max=204) & $19,46(11,82)$ & $33,73(13,03)$ \\
Aprendizagem de leitura visual (máx.=5) & $0,92(1,06)$ & $1,46(0,93)$ \\
Aprendizagem de leitura fonética (máx.=5) & $1,02(1,00)$ & $2,41(1,31)$ \\
Escrita de grafias visuais (máx.=5) & $0,15(0,37)$ & $0,17(0,39)$ \\
Escrita de grafias fonéticas (máx.=5) & $0,15(0,37)$ & $1,83(1,58)$ \\
\hline
\end{tabular}


Cardoso-Martins, C., Michalick, M.F., \& Pollo, T.C. (2006). O Papel do Conhecimento do Nome das Letras no Início da Aprendizagem da Leitura: Evidência de Indivíduos com Síndrome de Down.

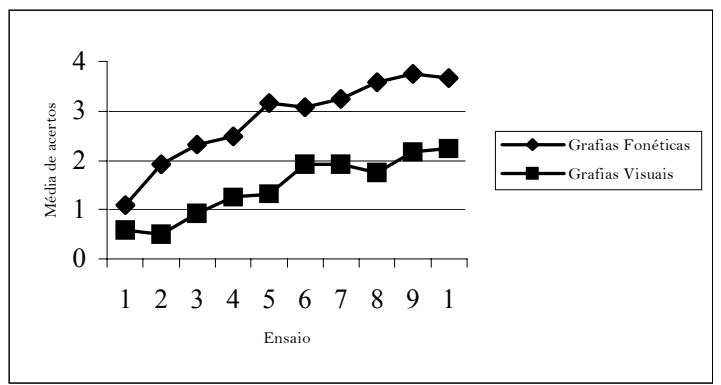

Figura 1. Indivíduos com conhecimento do nome das letras: número médio de repostas corretas por ensaio em função do tipo de grafia.

atingiram o critério antes de completar os 10 ensaios receberam escores totais nos ensaios remanescentes.) Como pode ser visto na Figura 1, os indivíduos que conheciam o nome das letras apresentaram o padrão de desempenho esperado. Isto é, eles apresentaram um desempenho relativamente superior para as grafias fonéticas do que para as grafias visuais, ao longo de todo o experimento. Por outro lado, como pode ser visto na Figura 2, os indivíduos que não conheciam o nome das letras apresentaram um desempenho muito fraco com ambos os tipos de grafias.

Uma ANCOVA foi realizada para avaliar a significância dessas impressões. Uma vez que os indivíduos que conheciam o nome das letras apresentaram um desempenho superior no PPVT, essa variável entrou na equação como uma covariante. As variáveis independentes foram o fator entresujeitos "conhecimento do nome das letras" (com vs. sem conhecimento) e os fatores inter-sujeitos "tipo de grafia simplificada" (visual vs. fonética) e "ensaio" (10 ensaios). A variável dependente foi o número de respostas corretas. (Um indivíduo do grupo com conhecimento do nome das letras foi excluído dessa análise por não haver feito o PPVT.).

O fator "tipo de grafia" foi significativo $[F(1,21)=16,82$, $p<0,001]$. De uma maneira geral, o resultado foi superior para as grafias fonéticas do que para as grafias visuais. Contudo, isso ocorreu apenas para o grupo de indivíduos com conhecimento do nome das letras, o que explica a interação significativa entre os fatores grupo e tipo de grafia $[F(1,22)=9,96, p<0,01]$.

O único outro fator principal significativo foi o fator "ensaio": o desempenho melhorou em ambas as tarefas com o tempo $[F(9,189)=2,60, p<0,05]$. Finalmente, embora o efeito de variações no PPVT não tenha sido significativo $[F(1,21)=0,96, \mathrm{~ns}]$, o PPVT interagiu significativamente com o fator "tipo de grafia" $[F(1,21)=4,52, p<0,05]$. Essa interação resultou do fato de que o desempenho no PPVT correlacionou-se significativamente apenas com o desempenho na tarefa com as grafias visuais. Nenhuma outra interação foi significativa.

Uma análise dos desempenhos individuais corroborou os resultados da análise de covariância. Nenhum indivíduo sem conhecimento do nome das letras atingiu o critério de dois ensaios corretos, quer para as grafias visuais quer para as fonéticas. No grupo com conhecimento do nome das letras,

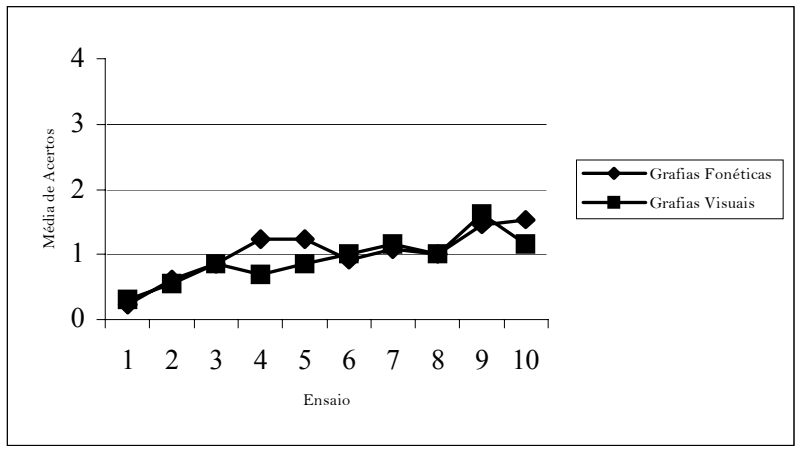

Figura 2. Indivíduos sem conhecimento do nome das letras: número médio de repostas corretas por ensaio em função do tipo de grafia.

por outro lado, seis indivíduos atingiram o critério com as grafias fonéticas, entre o terceiro e o nono ensaios. Um único indivíduo atingiu o critério com as grafias visuais e, mesmo assim, apenas no $10^{\circ}$ ensaio.

Conforme mencionamos anteriormente, um dos participantes do grupo com conhecimento do nome das letras leu 9 palavras. Em função da sua habilidade de leitura ser muito superior à dos outros membros do grupo, os quais, em geral, leram no máximo uma palavra corretamente, recalculamos a análise de covariância excluindo esse indivíduo da análise. Exatamente os mesmos resultados foram obtidos.

\section{Ditado das grafias}

O ditado das grafias revelou-se muito difícil, sobretudo para os indivíduos sem conhecimento do nome das letras. De fato, a maioria dos indivíduos desse grupo não escreveu nenhuma letra corretamente em qualquer um dos dois ditados. Em vista disso, apresentamos apenas os resultados para os indivíduos que escreveram pelo menos uma letra corretamente em qualquer um dos dois ditados. Nove indivíduos do grupo com conhecimento do nome das letras e três do grupo sem conhecimento satisfizeram esse critério. O número médio de letras escritas corretamente por esses indivíduos aparece na Tabela 3, separadamente para os dois tipos de grafias.

Os indivíduos com conhecimento do nome das letras lembraram-se de um número significativamente maior de letras para as grafias fonéticas do que para as grafias visuais [teste de Wilcoxon, $p<0,05]$. Tendo em vista o número muito pequeno de participantes, não calculamos a significância da diferença obtida entre os dois tipos de grafia para o grupo de indivíduos sem conhecimento das letras. Contudo, como pode ser visto na Tabela 3, esses indivíduos apresentaram um desempenho igualmente ruim em ambos os ditados.

Tabela 3

Número Médio de Letras Escritas Corretamente em Função do Grupo de Indivíduos e do Tipo de Grafia Simplificada

\begin{tabular}{lcc}
\hline Tarefa & $\begin{array}{c}\text { Sem conhecimento dos } \\
\text { nomes das letras }\end{array}$ & $\begin{array}{c}\text { Com conhecimento dos } \\
\text { nomes das letras }\end{array}$ \\
\hline Grafias Visuais & 0,08 & 0,33 \\
Grafias Fonéticas & 0,31 & 4,00 \\
\hline
\end{tabular}


Semelhantemente ao que tem sido encontrado com crianças cujo desenvolvimento é normal (Ex.: ver de Abreu \& Cardoso-Martins, 1998; Cardoso-Martins et al., 2002), o conhecimento do nome das letras parece ter interferido com a aprendizagem das grafias visuais pelos indivíduos com SD. Com efeito, pelo menos seis dos indivíduos com conhecimento do nome das letras apresentaram erros "fonéticos" no ditado das grafias visuais. Por exemplo, quatro deles escreveram a letra $B$ como a primeira letra para a palavra berço, cuja grafia visual começava com a letra $J$.

\section{Discussão}

Os resultados do presente estudo questionam a hipótese de Buckley (1985) de que indivíduos com síndrome de Down têm mais facilidade em aprender a ler visualmente do que através do processamento de relações letra-som nas palavras. Nossos participantes que não conheciam o nome das letras tiveram muita dificuldade em aprender a ler tanto as grafias fonéticas quanto as visuais. De fato, nenhum indivíduo que não conhecia o nome das letras atingiu o critério de aprendizagem em qualquer uma das duas tarefas de aprendizagem de leitura. Os indivíduos com conhecimento do nome das letras, por outro lado, mostraram mais facilidade com as grafias fonéticas do que com as grafias visuais.

Os indivíduos com conhecimento do nome das letras apresentaram um desempenho muito pobre na tarefa de aprendizagem das grafias visuais, tendo apresentado um resultado semelhante ao dos indivíduos sem conhecimento do nome das letras nessa tarefa. Por outro lado, seu desempenho na tarefa de aprendizagem com grafias fonéticas superou o desempenho dos indivíduos sem conhecimento do nome das letras. Com efeito, enquanto nenhum indivíduo sem conhecimento do nome das letras atingiu o critério de aprendizagem com as grafias fonéticas, metade dos indivíduos do grupo com conhecimento das letras mostrou esse desempenho.

Conforme mencionamos anteriormente, conjuntos diferentes de palavras foram utilizados para as grafias visuais e fonéticas. É pouco provável, no entanto, que a diferença favorecendo as grafias fonéticas entre os indivíduos com conhecimento das letras possa ter resultado de diferenças inesperadas entre os dois grupos de palavras. Com efeito, caso as palavras fonéticas fossem mais fáceis do que as palavras visuais, era de se esperar que os indivíduos sem conhecimento do nome das letras também apresentassem um desempenho superior na tarefa com as grafias fonéticas do que na tarefa com as grafias visuais. No entanto, nenhuma diferença foi observada entre os dois tipos de grafias para esse grupo. Além disso, apenas palavras comuns foram utilizadas em ambos os conjuntos. Finalmente, os dois conjuntos de palavras eram semelhantes em termos do número de fonemas, sílabas e letras.

Tampouco parece provável que a diferença entre os dois grupos na tarefa de aprendizagem de leitura com as grafias fonéticas possa ser explicada em termos da diferença no seu nível de desenvolvimento intelectual. Conforme descrevemos anteriormente, as nossas análises controlaram o efeito de variações no vocabulário receptivo. Além disso, o PPVT correlacionou-se apenas com o desempenho na tarefa de aprendizagem com as grafias visuais.

Os nossos resultados suportam, portanto, a hipótese de que o conhecimento do nome das letras incita os indivíduos a aprender a ler através do processamento de relações letrasom nas palavras. A razão para isso é que a utilização de pistas viso-fonológicas possibilita uma leitura muito mais acurada do que a utilização de pistas puramente visuais. Apesar de suas dificuldades fonológicas, os indivíduos com SD que participaram do nosso estudo mostraram-se capazes de utilizar seu conhecimento do nome das letras para aprender a ler através do processamento de relações letrasom nas palavras. Com efeito, esse conhecimento pareceu interferir de maneira negativa com a aprendizagem das grafias visuais.

Os resultados do nosso estudo também sugerem que a habilidade de processar relações letra-som nas palavras pode ser indispensável para que indivíduos com SD aprendam a ler. Independentemente do seu conhecimento do nome das letras, os indivíduos com SD apresentaram um desempenho muito pobre com as grafias visuais, em que as letras não simbolizavam sons. Com efeito, com exceção de um único indivíduo, nenhum indivíduo, com ou sem conhecimento das letras, atingiu o critério de aprendizagem com as grafias visuais.

É possível que a aprendizagem de conexões arbitrárias demande maior capacidade cognitiva do que a aprendizagem de conexões letra-som. Por exemplo, no modelo conexionista de Harm e Seidenberg (1999), um número reduzido de unidades escondidas afeta sobretudo a aprendizagem de palavras irregulares, deixando a habilidade de aprender a ler palavras regulares mais ou menos intacta. Os nossos resultados são consistentes com essa hipótese. Conforme mencionamos anteriormente, o desenvolvimento intelectual, avaliado através do PPVT, correlacionou-se apenas com a aprendizagem das grafias visuais.

O presente estudo apresenta várias limitações. Por exemplo, o estudo incluiu uma amostra relativamente pequena. Além disso, é possível que tenhamos criado grafias fonéticas muito simples. Conforme mencionamos anteriormente, o nome da primeira letra podia ser claramente detectado na pronúncia de todas as grafias fonéticas. Uma vez que o processamento de relações letrasom parece ser mais fácil quando a letra corresponde ao nome da letra do que quando ela corresponde ao fonema tipicamente representado pelaletra (Cardoso-Martins \& Batista, 2005; Treiman et al., 1996), é possível que os indivíduos com SD tivessem apresentado mais dificuldade com as grafias fonéticas caso elas não incluíssem relações letra-nome de letra, mas apenas relações letra-fonema. Essa hipótese é plausível, tendo em vista as dificuldades fonológicas dos indivíduos com SD. No entanto, em vista dos resultados obtidos para os indivíduos sem conhecimento do nome das letras, parece pouco provável que os indivíduos com conhecimento do nome das letras teriam aprendido a 
ler as grafias visuais mais facilmente do que as grafias fonéticas, caso essas grafias incluíssem apenas relações letrafonema.

Os resultados do presente estudo apresentam implicações teóricas e práticas importantes. Do ponto de vista pedagógico, a implicação é clara: programas de leitura para crianças com SD devem basear-se na instrução das relações entre as letras e os sons. Do ponto de vista teórico, nossos resultados sugerem que, independentemente da presença ou não de dificuldades fonológicas, o conhecimento das relações entre as letras e os sons é essencial para o progresso na aprendizagem da leitura em um sistema de escrita alfabético.

\section{Referências}

Buckley, S. (1985). Attaining basic educational skills: Reading, writing and number. In D. Lane \& B. Stratford (Eds.), Current apporaches to Down's syndrome (pp.315-343). New York: Praeger Press.

Cardoso-Martins, C. (2001). The Reading Abilities of Beginning Readers of Brazilian Portuguese: Implications for a Theory of Reading Acquisition. Scientific Studies of Reading, 5, 289-317.

Cardoso-Martins, C. \& Batista, A.C.E. (2005). O conhecimento do nome das letras e o desenvolvimento da escrita: Evidência de crianças falantes do português. Psicologia: Reflexão E̊ Crítica, 18, 330-336.

Cardoso-Martins, C., Pennington, B.F., \& Moon, J. (2006). Reading components in Down Syndrome. (Manuscrito nãopublicado)

Cardoso-Martins, C., Resende, S.M., \& Rodrigues, L.A. (2002). Letter name knowledge and the ability to learn to read by processing letter-phoneme relations in words: evidence from Brazilian Portuguese-speaking children. Reading and Writing: An Interdisciplinary Journal, 15, 409-432.

Cardoso-Martins, C., Rodrigues, L.A., \& Ehri, L.C. (2003). Place of environmental print in reading development: Evidence from nonliterate adults. Scientific Studies of Reading, 7, 335-355.

De Abreu, M. \& Cardoso-Martins, C. (1998). Alphabetic access route in beginning reading acquisition in Portuguese: the role of letter-name knowledge. Reading and Writing: An Interdisciplinary Journal, 10, 85-104.
Ehri, L. (1992). Reconceptualizing the development of sight word reading and its relationship to recoding. In P. Gough, L. Ehri, \& R. Treiman (Eds.), Reading acquisition (pp.107-143). Hillsdale: Lawrence Erlbaum.

Ehri, L. (2002). Phases of acquisition in learning to read words and implications for teaching. In R. Stainthorp \&.P. Tomlinson (Eds.), Psychological Aspects of Education:Current Trends Number 1. British Journal of Educational Psychology Series II.

Ehri, L. \& Wilce, L. (1985). Movement into reading: Is the first stage of printed word learning visual or phonetic? Reading Research Quarterly, 20, 163-179.

Frith, U. (1985). Beneath the surface of developmental dyslexia. In K. Patterson, J. Marshall, \& M. Coltheart (Eds.), Surface dyslexia: Neuropsychological and cognitive studies of phonological reading (pp.301-330). Hillsdale: Lawrence Erlbaum.

Gough, P. \& Hillinger, M. (1980). Learning to read: an unnatural act. Bulletin of the Orton Society, 30, 179-196.

Harm, M.W. \& Seidenberg, M.S. (1999). Phonology, reading acquisition, and dyslexia: Insights from connectionist models. Psychological Review, 106, 491-528.

Marsh, G., Friedman, M., Welch, V., \& Desberg, P. (1981). A cognitive-developmental theory of reading acquisition. In G. Mackinnon \& T. Waller (Eds.), Reading research: Advances in theory and practice (pp.199-221). San Diego: Academic Press.

Pennington, B.F., Moon, J., Edgin, J., Stedron, J., \& Nadel, L. (2003). The neuropsychology of Down syndrome: Evidence for hippocampal dysfunctions. Child Development, 74, 75-93.

Pinheiro, A. \& Keys, K. (1987). A word frequency count in Brazilian Portuguese. University of Dundee, Dundee. (Manuscrito nãopublicado)

Seymour, P.H.K. \& Elder, L. (1986). Beginning reading without phonology. Cognitive Neuropsychology, 3, 1-36.

Treiman, R., Tincoff, R., \& Richmond-Welty, E.D. (1996). Letter names help children to connect print and speech. Developmental Psychology, 32, 505-514. 